\title{
Implementing the Health Early Warning System based on syndromic and event-based surveillance at the $2019 \mathrm{Hajj}$
}

Kingsley Lezor Bieh, ${ }^{1}$ Anas Khan, ${ }^{1,2}$ Saber Yezli, ${ }^{1}$ Ahmed El-Ganainy, ${ }^{1}$ Sari Asiri, ${ }^{3}$ Badriah Alotaibi, ${ }^{3}$ Sujoud Ghallab, ${ }^{1}$ Amgad Elkholy, ${ }^{4}$ Abdinasir Abubakar ${ }^{4}$ and Hani Jokhdar ${ }^{3}$

${ }^{1}$ Global Center for Mass Gatherings Medicine (WHO Collaborating Center for Mass Gatherings Medicine) Ministry of Health, Riyadh, Saudi Arabia. ${ }^{2}$ Emergency Medicine Department, College of Medicine, King Saud University, Riyadh, Saudi Arabia. ${ }^{3}$ Ministry of Health, Riyadh, Saudi Arabia. ${ }^{4}$ World Health Organization Eastern Regional Office for the Eastern Mediterranean, Cairo, Egypt. (Correspondence to: Kingsley Lezor Bieh: blezor@moh.gov. sa; kinslezor@gmail.com).

\begin{abstract}
Background: During the 2019 Hajj, the Ministry of Health in Saudi Arabia implemented for the first time a health early warning system for rapid detection and response to health threats.

Aims: This study aimed to describe the early warning findings at the Hajj to highlight the pattern of health risks and the potential benefits of the disease surveillance system.

Methods: Using syndromic surveillance and event-based surveillance data, the health early warning system generated automated alarms for public health events, triggered alerts for rapid epidemiological investigations and facilitated the monitoring of health events.

Results: During the deployment period (4 July-31 August 2019), a total of 121 automated alarms were generated, of which 2 events (heat-related illnesses and injuries/trauma) were confirmed by the response teams.

Conclusion: The surveillance system potentially improved the timeliness and situational awareness for health events, including non-infectious threats. In the context of the current COVID-19 pandemic, a health early warning system could enhance case detection and facilitate monitoring of the disease geographical spread and the effectiveness of control measures.
\end{abstract}

Keywords: syndromic surveillance, event-based surveillance, early warning, Hajj, mass gathering, pilgrim

Citation: Bieh KL; Khan A; Yezli S; El-Ganainy A; Asiri S; Alotaibi B; et al. Implementing the Health Early Warning System based on syndromic and event-based surveillance at the 2019 Hajj. East Mediterr Health J. 2020;26(12):1570-1575. https://doi.org/10.26719/emhj.20.129

Received: 18/05/20; accepted: 11/06/20

Copyright (C) World Health Organization (WHO) 2020. Open Access. Some rights reserved. This work is available under the CC BY-NC-SA 3.0 IGO license (https://creativecommons.org/licenses/by-nc-sa/3.o/igo).

\section{Background}

In August 2019, 2489406 Muslim pilgrims, of which $74.5 \%$ were international pilgrims, performed the 2019 (1440) Hajj in Makkah, Saudi Arabia. Over half (55.6\%) of all pilgrims were males, and $9.2 \%$ of pilgrims were Saudi nationals (excludes non-Saudi residents) (1).

Disease prevention and control remains a national, regional and international public health priority during Hajj $(2,3)$. Among various interventions, the deployment of enhanced disease surveillance system is recommended for mass gatherings to facilitate rapid detection and response to health threats (4). A case-based infectious diseases surveillance system, which uses an electronic portal for rapid data management, is deployed for Hajj (5). However, the focus on specific infectious threat is a recognized limitation of the surveillance system (6).

Syndromic and event-based surveillance (EBS) systems complement routine case-based surveillance systems in mass gatherings settings $(4,7)$. By using data that precede diagnostic confirmation, syndromic surveillance facilitates prompt detection of existing threats, improves the surveillance for emerging diseases and provides an opportunity for rapid response $(4,8)$. Event-based surveillance also ensures timeliness through pre-diagnostic data analysis; it captures unstructured data from diverse settings, including health care, media and community settings, to trigger public health alert and response (9).

The systematic real-time (or near real-time) reporting of both syndromic surveillance and EBS data thus provides an opportunity for early warning, especially in an international mass gathering context where timely detection and response is required for prompt risk mitigation and prevention. In addition, the ongoing systematic collection and analysis of surveillance data could improve situational awareness, provide reassurance of the absence of public health threats and guide continuing public health decision making $(4,7)$. Given these potential benefits, the Ministry of Health in Saudi Arabia implemented a health early warning system (HEWS) during the 2019 (1440) Hajj. The health early warning system used both syndromic and EBS data to rapidly detect potential public health threats, triggered corresponding alerts for rapid epidemiological investigations and monitored the trend of confirmed health events during the 2019 (1440) Hajj. This study aims to describe the early warning findings at the Hajj to highlight the pattern of health risks and the potential benefits of the disease surveillance system. 


\section{Methods}

This study is a descriptive analysis of surveillance data from the HEWS implementation processes during the 2019 Hajj. The projected target coverage of HEWS is at least $80 \%$ of health facilities (hospitals and primary health centres), but coverage was limited to only Ministry of Health hospitals in 2019. The included syndromes and events were identified through an international technical consultation organized by the World Health Organization (WHO) and the Ministry of Health (Table 1). A web-based electronic solution, which was anchored on an existing information exchange and data analytic tool, was developed for HEWS data management. Relevant data were pooled from hospital electronic medical records (EMRs) and integrated in a central database to provide a unified data source.

The raw data, including the International Classification of Diseases (ICD) 10 provisional diagnosis, were extracted and read periodically (hourly) from the central database, and then applied with the defined logic for priority syndromes and events to generate automated alarm on the HEWS dashboards. Additionally, a hotline was established for the report of public health events directly to the Command Centre. Initial alarm thresholds were set based on the benchmarks in a WHO regional syndromic surveillance system and the moving average statistical algorithms (8). Each alarm was reviewed by two epidemiologists before an alert was issued for field investigation. Response was integrated with those of the pre-existing enhanced infectious disease surveillance system for Hajj $(5,6)$. The dissemination of this surveillance finding is approved by the Saudi Ministry of Health surveillance team. Supplementary data will only be shared on request after a review by the surveillance team.

\section{Results}

The surveillance data was reported from the emergency and outpatient departments of 16 Ministry of Health hospitals. A total of 409098 consultations $(62.18 \%$ among non-pilgrims) were reported during the deployment period. The number of daily consultations peaked during the period of Hajj rites (9-14 August 2019), and 80.2\% of the total consultations during this period were among pilgrims (Figure 1).

Males represented $54.4 \%$ of all consultations and $62.8 \%$ of those among pilgrims. The proportion of consultations for each age group of pilgrims were 50\% ( $45-64$ years), $29.6 \%$ ( $25-44$ years), $14.9 \%$ ( $\geq 65$ years) and $4.9 \%$ ( $\leq 24$ years).

During the deployment period, 121 automated alarms were generated for the following syndromes: acute febrile syndrome without rash (60), severe acute respiratory infections (18), acute febrile syndrome with neurological manifestation (14), acute febrile syndrome with rash (10), heat-related illnesses (HRI) (10), acute jaundice syndrome (7), and chemical injuries (2). Of these, 49 field investigations were conducted and an additional alert was issued for trauma/injuries based on analysis of a hotline-generated event, in the aftermath of an unexpected heavy rainfall in the Hajj areas.

The response team confirmed two health events (HRI and trauma/injuries) as depicted in Figure 2. The suspected HRI cases included citizens of 56 countries. Furthermore, females represented $46.7 \%$ of suspected HRI cases and the majority (79\%) were reported from Arafat and Mina hospitals. The trauma/injury cases mostly involved males (66.7\%), and the age group distribution of cases were $<15$ years $(2.08 \%), 15$-24years (12.5\%), 25-44years (36.45\%), 45-64years (29.16\%), $>64$ years $(9.37 \%)$ and missing (10.41\%). The peak daily mean response time (period between a public health alert and report of event status by investigation teams). was 3.44 hours and the lowest daily mean response time was 1.47 hours. No other priority syndromes or health events were detected by HEWS and no cases of priority diseases were reported by the pre-existing surveillance system from the HEWS reporting sites.

\section{Discussion}

The health early warning system improved the timeliness of reporting and detected two non-infectious health risks during the 2019 Hajj. The development and linkage of HEWS with pre-existing data management technolo-

\begin{tabular}{ll}
\hline Table 1 List of priority syndromes and events & \\
\hline Syndromes & \multicolumn{1}{c}{ Events } \\
\hline Acute febrile syndrome without rash & Food poisoning \\
Acute febrile syndrome with rash & Heat-related illness \\
Acute febrile syndrome with neurological manifestation & Chemical, biological, radiological and nuclear emergencies \\
Acute jaundice syndrome & Trauma/injuries \\
Acute flaccid paralysis (AFP) & Cluster of cases or unusual health events \\
Acute haemorrhagic fever & Detection of unusual pathogens \\
Severe acute respiratory infections & - \\
Acute respiratory distress syndrome & - \\
Acute watery diarrhoea & - \\
Acute bloody diarrhoea & - \\
\hline
\end{tabular}




\section{Figure 1 Graphical representation of the total number of consultations and reporting sites}

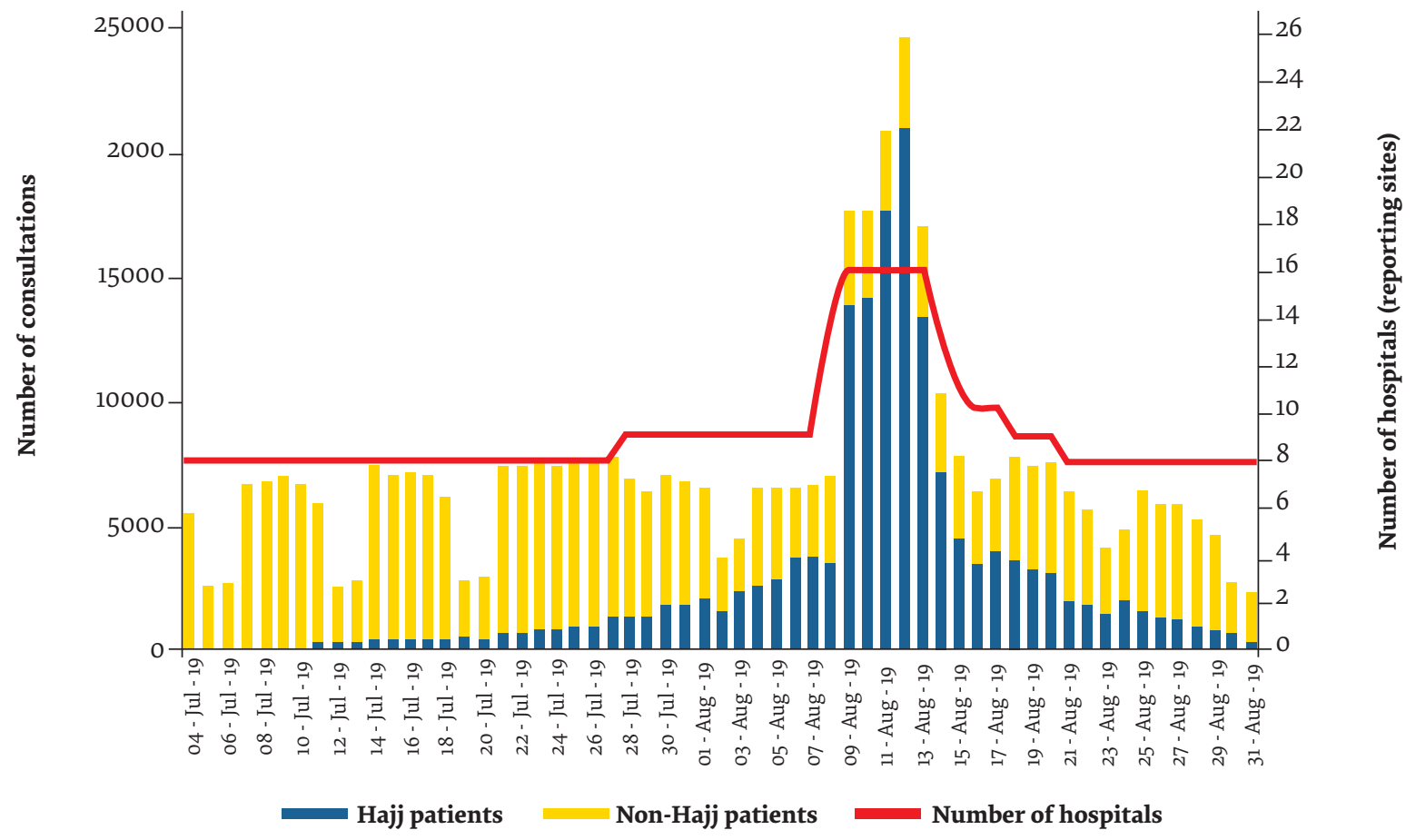

gy within the Ministry of Health promoted the effective use of available resources. In addition, the use of secondary data captured primarily for clinical consultation purposes ensured that additional data collection tasks were not assigned to already over-burdened health-care professionals in Hajj. Similar principles informed the

Figure 2 Epi-curve of confirmed priority health events during the 2019 Hajj

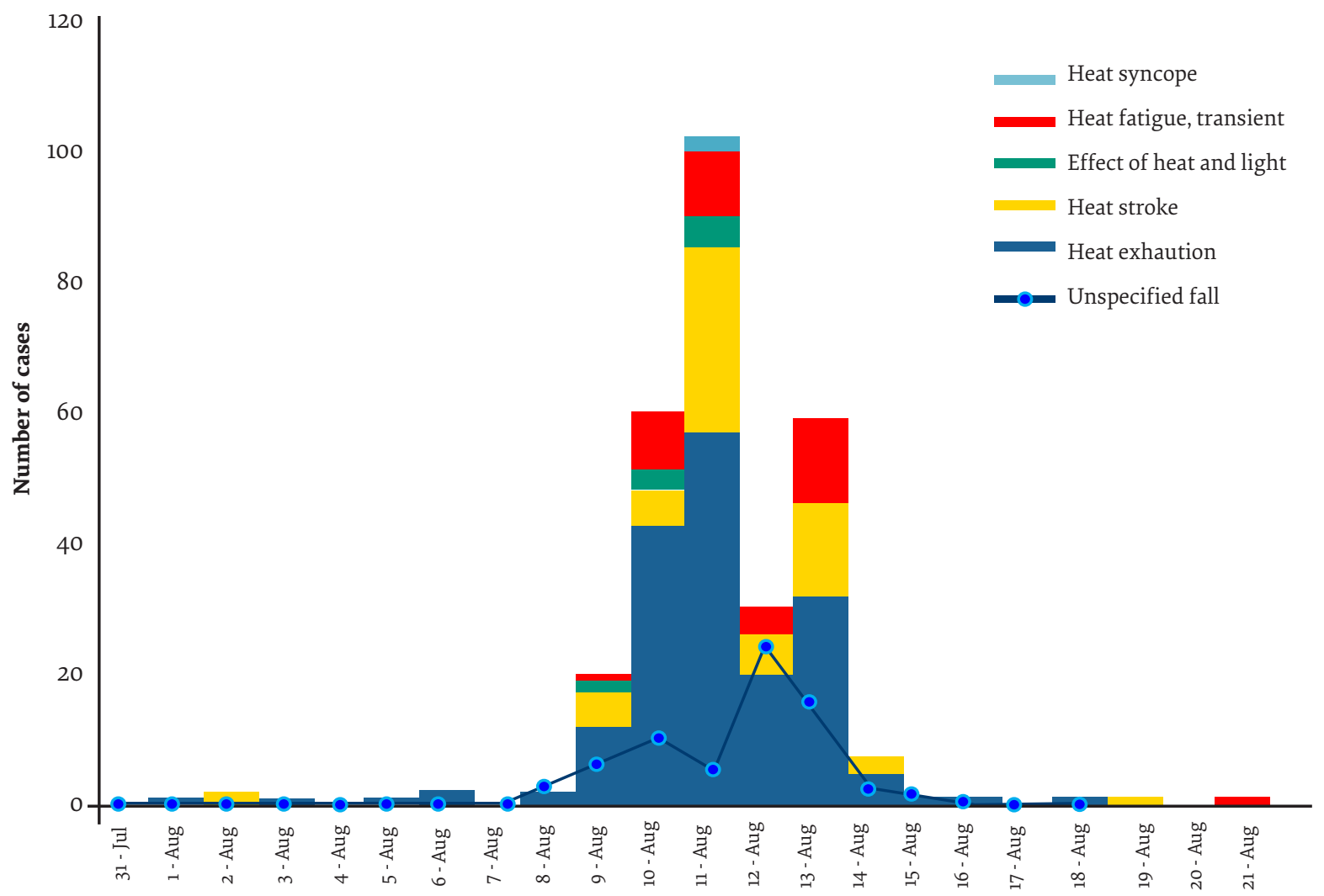


use of existing data in other mass gatherings syndromic surveillance systems $(10,11)$. Electronic data management is fast becoming an integral part of most early warning systems due to the benefits of promoting timeliness of reporting, and minimizing the significant manpower needs and human errors that are often associated with manual data management (10).

The number of automated alarms increased with daily consultation rates, and nearly half of all generated alarms were made for acute febrile syndrome. Indeed, fever unspecified was among the leading ICD 10 provisional diagnosis at the 2019 Hajj, and the variation in number of cases had no major public health implication. Since a missed event in the Hajj could have profound health security impacts, the setting of HEWS notification thresholds favoured increased sensitivity of the system and by implication the number of false alarms. Anticipating the stretch of field response resources, the dashboard verification of automated alarms reduced the number of investigation alerts by more than half.

The detected health events (HRI and injuries) were monitored and controlled with appropriate mitigating measures, including redeployment of manpower resources. While the number of suspected HRI cases declined sharply after an initial peak on the Day of Arafat (11 August) due to an unexpected heavy rainfall, more pilgrims were injured from falls on the wet slippery surfaces. In contrast to sporting mass gatherings where injuries often arise from athletic activities, the risk of injuries in the Hajj is predominantly heightened by crowdrelated incidents $(3,12)$. Heat-related illnesses are among the leading causes of morbidity and mortality at the Hajj, when the pilgrimage is held during the summer months (13-15). The HEWS surveillance finding is consistent with historical data regarding the geographical distribution of HRI cases during Hajj $(13,14)$. A plausible reason for the high HRI disease burden in Mina and Arafat is the intensified physical exertion and increased exposure of pilgrims to hot weather as they perform the required Hajj rites in mostly open and unsheltered areas.

In future Hajj seasons, HEWS aims to capture data from at least $80 \%$ of all health facilities and incorporate non-facility based reporting sites, such as internet and social media platforms and over-the-counter drug sales records. Studies have shown that non-health facility based data collection improves the timeliness of syndromic surveillance systems $(9,16)$. Conceivably, the cooperation of countries sending pilgrims to the Hajj, especially countries setting up clinics to assist in providing care for their own pilgrims, is needed for the integration of their health clinics to the HEWS database. To achieve this, the Ministry of Health would set interoperability standards and ensure that data sharing occurs in a highly secured virtual environment. Under the International Health Regulation (IHR 2005), countries ought to implement and maintain functional EBS and indicator-based surveillance systems to meet the target for enhanced surveillance capacity (17). Expanding HEWS as a national disease surveillance system would contribute to meeting this global health security target.

\section{Limitations}

As a limitation, the periodic (hourly) data extraction from the central database rendered HEWS a near real-time surveillance system. In non-mass gatherings settings, this hourly time-lag may be nearly insignificant. However, in reality some pilgrims depart from the health facility within one hour of their arrival for a consultation visit. In a crowded setting where pilgrims are constantly mobile and have no stable addresses, identifying cases before they depart from the health-care facility is both logistically desirable and risks mitigating during response. However, nearly all response feedbacks were received within the stipulated period (6 hours) to guide ongoing decision-making, primarily due to the linkage of HEWS with the response resources of the pre-existing surveillance system. Preliminary validation reports showing around $10-20 \%$ of missing data in the central database may have compromised the quality of HEWS data. The finding of incomplete entries by physicians is consistent with those of other similar disease surveillance systems $(10,18)$. Additionally, potential public health threats, particularly less severe cases presenting to primary health centres, could have been missed since the system coverage was limited to 16 Ministry of Health hospitals in the Hajj areas. However, there were no reports of any major health threats from the pre-existing infectious disease surveillance system, which had a broader coverage.

\section{Conclusion}

This study provides valuable insight into the benefits of an early warning system in an international mass gathering context, with prevalent global health security risks. It potentially improves timeliness and the situational awareness for health events, including non-infectious threats. In the context of the current COVID-19 pandemic, HEWS could enhance case detection and facilitate monitoring of the disease geographical spread and the effectiveness of control measures.

Funding: None.

Competing interests: None declared. 


\section{Mise en œuvre du système d'alerte sanitaire précoce basé sur la surveillance syndromique et fondée sur les événements lors du Hadj de l'année 2019}

\section{Résumé}

Contexte : Au cours du Hadj de l'année 2019, le Ministère de la Santé d'Arabie saoudite a mis en place pour la première fois un système d'alerte précoce en matière de santé pour une détection des menaces sanitaires et une riposte rapides face à celles-ci.

Objectifs : La présente étude avait pour objectif de présenter les résultats de l'alerte précoce lors du Hadj afin de mettre en évidence le schéma des risques sanitaires et les avantages potentiels du système de surveillance des maladies.

Méthode : À l'aide de la surveillance syndromique et des données de surveillance basée sur les événements, le système d'alerte sanitaire précoce a généré des alarmes automatisées pour les événements de santé publique, a déclenché des alertes en vue d'enquêtes épidémiologiques rapides et a facilité le suivi des événements de santé.

Résultats : Au cours de la période de déploiement (4 juillet-31 août 2019), un total de 121 alarmes automatiques ont été générées, dont deux événements (maladies et blessures/traumatismes liés à la chaleur) ont été confirmés par les équipes d'intervention.

Conclusions : Le système de surveillance a potentiellement amélioré la notification en temps voulu des événements de santé et la connaissance des situations concernant ces événements, y compris les menaces non infectieuses. Dans le contexte de la pandémie actuelle de COVID-19, un système d'alerte précoce permettrait d'améliorer la détection des cas et de faciliter le suivi de la propagation géographique de la maladie ainsi que l'efficacité des mesures de lutte.

$$
\begin{aligned}
& \text { تنفيذ نظام الإنذار الصحي المبكر القائم على ترصّد المتلازمات والأحداث في موسم الحج لعام } 2019 \\
& \text { كينجسلي لزور بيه، أنس خان، صابر يزلي، أحمد الجنايني، ساري عسيري، بدرية العتيبي، سجود غلاب، أبجد الخولي، عبدي-ناصر أبو بكر، هاني } \\
& \text { جوخضار } \\
& \text { الخالاصة }
\end{aligned}
$$

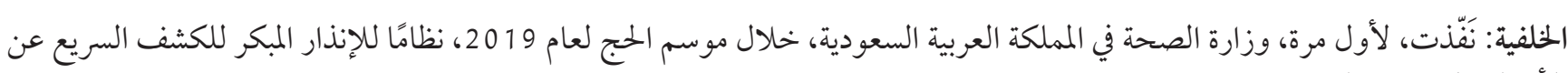

$$
\begin{aligned}
& \text { الأخطار الصحية والاستجابة لفا. لألفان. } \\
& \text { الأهداف: هدفت هذه الدراسة إلى وصف نتائج الإنذار المبكر في موسم الحج لتسليط الضوء على نمط المخاطر الصحية والفو ائد المحتملة لنظام } \\
& \text { ترصّد الأمراض. } \\
& \text { طرق البحث: أصدر نظام الإنذار الصحي المبكر، باستخدام بيانات ترصّد المتلازمات والأحداث، إنذارات آلية لأحداث صحية عامة، وأطلق }
\end{aligned}
$$

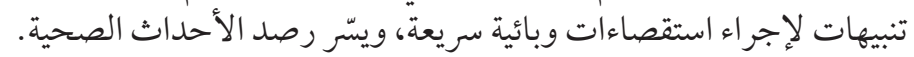

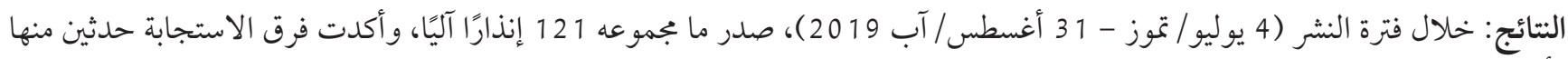

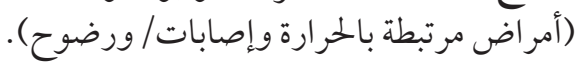

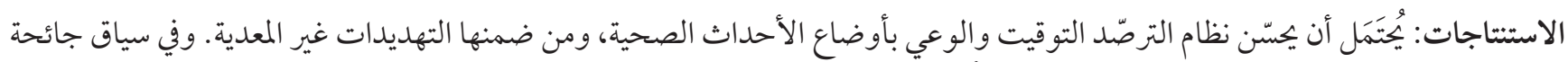

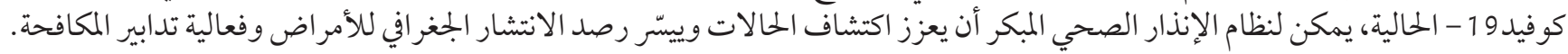

\section{References}

1. General Authority of Statistics. Hajj Statistics, Kingdom of Saudi Arabia, 2019. Riyadh: General Authority of Statistics; 2019 (https://www.stats.gov.sa/en/28).

2. World Health Organization Regional Office for the Eastern Mediterranean (WHO/EMRO). WHO statement on successful conclusion of hajj 1440/2019. Cairo: WHO/EMRO; 2019 (http://www.emro.who.int/media/news/who-statement-on-successful-conclusion-of-hajj-14402019.html).

3. Memish ZA, Steffen R, White P, Dar O, Azhar EL, Sharma A, et al., Mass gatherings medicine: public health issues arising from mass gathering religious and sporting events. Lancet. 2019;393(10185):2073-2084.

4. World Health Organization Regional Office for the Eastern Mediterranean (WHO/EMRO). Public health for mass gatherings: key considerations. Cairo: WHO/EMRO; 2015.

5. Memish ZA, Zumla A, Alhakeem RF, Assiri A, Turkestani A, Al-Harby KD, et al. Hajj: infectious disease surveillance and control. The Lancet. 2014;383(9934):2073-2082. 
6. Alotaibi BM, Yezli S, Bin Saeed A-AA, Turkestani A, Alawam AH, Bieh KL Strengthening health security at the Hajj mass gatherings: characteristics of the infectious diseases surveillance systems operational during the 2015 Hajj. J Travel Med. 2017;24(3):taw087.

7. McCloskey B, Endericks T, Catchpole M, Zambon N, Mclauchlin J, Shetty N, et al. London 2012 Olympic and Paralympic Games: public health surveillance and epidemiology. The lancet. 2014;383(9934):2083-2089.

8. Triple S - Guidelines for designing and implementing a syndromicsSurveillance system. Paris: French Institute for Public Health Surveillance; 2013.

9. Keller M, Blench M, Tolentino H, Friefeld CC, Mandl K, Mawudeku A, et al. Use of unstructured event-based reports for global infectious disease surveillance. Emerg Infect Dis. 2009;15(5):689.

10. Elliot AJ, Hughes HE, Hughes TC, Locker TE, Shannon T, Heyworth J, et al. Establishing an emergency department syndromic surveillance system to support the London 2012 Olympic and Paralympic Games. Emerg Med J. 2012;29(12):954-960.

11. Williams CJ, Schenkel K, Eckmanns T, Altmann D, Krause G. FIFA World Cup 2006 in Germany: enhanced surveillance improved timeliness and detection. Epidemiol Infect. 2009;137(4):597-605.

12. Yancey AH, Fuhri PD, Pillay Y, Greenwald I., et al., World Cup 2010 planning: an integration of public health and medical systems. Public Health. 2008;122(10):1020-9.

13. Khogali M. Epidemiology of heat illnesses during the Makkah Pilgrimages in Saudi Arabia. Int J Epidemiol. 1983;12(3):267-273.

14. Abdelmoety DA, El-Bakri NK, Almowalld WO, Turskestani ZA, Bugis BA, Baseif E, et al. Characteristics of heat illness during Hajj: a cross-sectional study. Biomed Res Int. 2018;2018:5629474.

15. Ministry of Health. Statistics Year Book 1438H, Ministry of Health, Kingdom of Saudi Arabia. Riyadh: Ministry of Heath; 2018 (https://www.moh.gov.sa/en/Ministry/Statistics/book/Pages/default.aspx).

16. Hogan WR, Tsui F-C, Ivanov O, Gesteland P, Grannis S, Overhage J, et al., Detection of pediatric respiratory and diarrheal outbreaks from sales of over-the-counter electrolyte products. J Am Med Inform Assoc. 2003;10(6):555-562.

17. World Health Organization, International Health Regulations (IHR): Joint External Evaluation (JEE): country Implementation guide. Geneva: World Health Organization; 2017.

18. Napoli C, Riccardo F, Declich S, Dente M, Pompa M, Rizzo C, et al., An early warning system based on syndromic surveillance to detect potential health emergencies among migrants: results of a two-year experience in Italy. Int J Environ Res Public Health. 2014;11(8):8529-8541. 